\title{
A Comunicação Inclusiva como princípio de conversa para a Educação Permanente no SUS: O Projeto "Caminhos do Cuidado" como Laboratório
}

\author{
Inclusive communication as a conversation principle for permanent education \\ in SUS: The project "Care Paths" as a laboratory
}

La comunicación inclusiva como principio de conversación para la educación
permanente en el SUS: el proyecto "Caminos del Cuidado" como Laboratorio

Ester Cristina Machado Ruas ${ }^{1}$

\begin{abstract}
Resumo
Este artigo apresenta a comunicação como um componente crítico capaz de contribuir para um processo de educação permanente em saúde. Começamos por descrever o projeto de formação de agentes comunitários de saúde, auxiliares e técnicos de enfermagem em saúde mental, álcool e outra drogas denominado "Caminhos do Cuidado" e a abordagem pedagógica e epistemológica abraçada. A proposta deste itinerário formativo redundou na participação de 284.868 alunos em todo o território, baseava-se no cotidiano do trabalho, das práticas e vivências de cada profissional de saúde no seu território. Esse itinerário foi laboratório para a experiência da comunicação inclusiva, dialógica e participativa, como mobilizadora dos atores envolvidos com a educação permanente. E, a entrevista semiestruturada foi o instrumento relacional encontrado, que permitiu estabelecer um vínculo com o sujeito e apropriar os sentidos dados em seus discursos como prática política e ideológica.
\end{abstract}

\begin{tabular}{|c|c|}
\hline & Acesse este artigo online \\
\hline \multirow{2}{*}{ 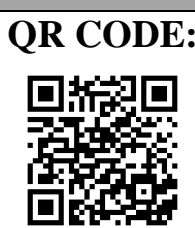 } & $\begin{array}{l}\text { Website: } \\
\text { http://www.revistas.ufg.br/index.php/ci }\end{array}$ \\
\hline & $\begin{array}{l}\text { DOI: } \\
\text { http://dx.doi.org/10.5216/ci.v20i3.49321 }\end{array}$ \\
\hline
\end{tabular}

Palavras chaves: Comunicação Inclusiva. Educação Permanente. Cuidado.

Abstract

This article presents the communication as a critical component capable of contributing to a process of permanent education in health. We begin by describing the project of training community health agents, nursing auxiliaries and technicians in mental health, alcohol and other drugs called "Paths of Care" and the pedagogical and epistemological approach embraced. The proposal of this training itinerary resulted in the participation of 284,868 students throughout the territory, based on the daily work, practices and experiences of each health professional in its territory. This itinerary was a laboratory for the experience of inclusive, dialogic and participative communication, as a mobilizer of the actors involved with permanent education. And, the semi-structured interview was the relational instrument found, which allowed to establish a bond with the subject and to appropriate the senses given in his speeches as a political and ideological practice.

Keywords: Inclusive Communication. Continuing Education. Care.

\section{Resumen}

\footnotetext{
${ }^{1}$ Doutora em Ciências Sociais pelo Programa de Pós-Graduação em Informação e Comunicação em Saúde do Instituto de Comunicação e Informação Científica da Fundação Oswaldo Cruz/Fiocruz. E-mail crisruastb@gmail.com.
}

Comun. \& Inf., Goiânia, GO, v. 20, n. 3, p. 84-98, out./dez. 2017 
Este artículo presenta la comunicación como un componente crítico capaz de contribuir a un proceso de educación permanente en salud. Comenzamos por describir el proyecto de formación de agentes comunitarios de salud, auxiliares y técnicos de enfermería en salud mental, alcohol y otras drogas denominado "Caminos del Cuidado" y el abordaje pedagógico y epistemológico abrazado. La propuesta de este itinerario formativo redundó en la participación de 284.868 alumnos en todo el territorio, se basaba en el cotidiano del trabajo, de las prácticas y vivencias de cada profesional de salud en su territorio. Este itinerario fue laboratorio para la experiencia de la comunicación inclusiva, dialógica y participativa, como movilizadora de los actores involucrados en la educación permanente. Y la entrevista semiestructurada fue el instrumento relacional encontrado, que permitió establecer un vínculo con el sujeto y apropiar los sentidos dados en sus discursos como práctica política e ideológica.

Palabras claves: Comunicación Inclusiva. Educación Permanente. Cuidado.

\section{INTRODUÇÃO}

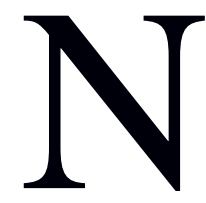

ão faltam justificativas para se trazer à tona o debate sobre a necessidade de cuidado ampliado e humanizado em saúde mental. Para fazer frente a reinserção social desse sujeito dentro da rede de cuidado, em outubro de 2013, foi lançado o Projeto Caminhos do Cuidado, voltado para a formação em saúde mental, crack, álcool e outras drogas dos agentes comunitários de saúde (ACS) e auxiliares e técnicos em enfermagem (ATEnfs) da Atenção Básica.

A proposta, iniciada pelos estados do Acre, Pernambuco, Paraná, Rio Grande do Sul, São Paulo e Distrito Federal, integra o programa do governo federal Crack, É Possível Vencer, lançado em 2011, e inspirou-se no lema da $3^{\text {a }}$ Conferência Nacional de Saúde Mental - Cuidar sim. Excluir, não! - , tendo como meta capacitar os 290.760 profissionais de saúde até o fim deste ano de 2014.

Sob a coordenação do Instituto de Comunicação e Informação Científica e Tecnológica em Saúde (ICICT), da Fundação Oswaldo Cruz (Fiocruz) do Rio de Janeiro, do Grupo Hospitalar Conceição (GHC), de Porto Alegre e, por meio de convênio com o Departamento de Gestão da Educação na Saúde da Secretaria de Gestão do Trabalho e da Educação na Saúde do Ministério da Saúde (Deges/Sgtes/MS), o Caminhos do Cuidado buscou articular-se com as instituições do SUS protagonistas da formação desses trabalhadores, entre elas, secretarias e conselhos de saúde, escolas técnicas, centros formadores de recursos humanos e escolas de Saúde Pública.

Os esforços iniciais foram dedicados à estruturação da equipe do projeto, uma verdadeira orquestração de múltiplas e distintas competências. A composição se dá por uma equipe nacional, denominada de grupo condutor, seguida da coordenação executiva, núcleo 
pedagógico e acadêmico, coordenações macrorregionais, equipe de comunicação e equipe de infraestrutura, além de equipes estaduais, formada por um coordenador de nível superior, com experiência mínima de seis anos, na área de gestão e/ ou coordenação de projetos — este definido em conjunto com o estado. Cabia ao coordenador estadual elaborar, acompanhar e avaliar os cronogramas de formação no estado.

A formação em saúde mental dos ACS e um ATEnfs por equipe de Saúde da Família (ESF), teve como peça chave para o êxito do processo, o envolvimento e o reconhecimento de todas as escolas e centros formadores de recursos humanos integrantes da Rede de Escolas Técnicas do SUS (RET-SUS) — atualmente, 40.

\section{FORMAÇÃO EM LARGA ESCALA: UMA PROPOSTA DE ARQUITETURA PEDAGÓGICA}

Optou-se por trabalhar uma experiência inovadora. O projeto começa com a seleção de educadores e formação dos orientadores de aprendizagem que capacitam os tutores no processo de formação em saúde mental, crack, álcool e outras drogas. Os tutores, por sua vez, acompanham os ACS e ATEnfs ao longo de todo o curso.

A proposta conta com três etapas de formação. Começa com a seleção de quinze educadores responsáveis pela formação de oitenta orientadores de aprendizagem que, por sua vez, formam mil e quatrocentos tutores que acompanham os ACS e ATEnfs ao longo de todo o curso. Os educadores, pesquisadores com reconhecida competência e atuação no tema, participaram também da elaboração do material pedagógico desenvolvido para o curso. No sítio do projeto, http://observatorio.caminhosdocuidado.org, é possível ter acesso a todo o material do curso, bem como a identificação e perfil dos profissionais envolvidos no mesmo.

No contexto do projeto, há também a chamada Comunidade de Práticas, voltada para a interação virtual dos profissionais envolvidos. Esse espaço permitiu aos alunos encontrar soluções para um problema da comunidade ou inerente ao aprendizado diário.

Por meio da Educação a Distância (EaD), essas comunidades apoiam a construção e o desenvolvimento dos programas e cursos, através de novas tecnologias de comunicação para criar espaços de aprendizagem, geralmente por meio de fórum, chat, lista de discussão, site, biblioteca virtual etc. Portanto, além das aulas teóricas, os participantes de Caminhos do Cuidado têm à disposição uma plataforma virtual para a constituição de comunidades virtuais 


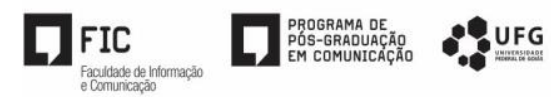

de agentes comunitários de saúde, auxiliares e técnicos em enfermagem da Atenção e tutores e orientadores de aprendizagem.

Por fim, os 290.760 agentes comunitários de saúde e auxiliares e técnicos em enfermagem recebem uma formação de 60 horas, sendo 40 horas presenciais e 20 horas de dispersão. A capacitação é feita de forma descentralizada, respeitando os pactos realizados com as instituições dos estados. O curso, cujo foco é a Política de Atenção Integral aos Usuários de Álcool e Outras Drogas, norteado pela redução de danos aos usuários de drogas ilícitas, ofereceu um conjunto de estratégias e conhecimentos em saúde mental, acolhimento e cuidado integral do usuário. Os objetivos da formação é fazer com que o aluno aproprie-se do processo de reforma psiquiátrica e da política de saúde mental, com ênfase na rede de atenção psicossocial, na reintegração social e na cidadania das pessoas usuárias de álcool e outras drogas, discutir e construir o papel do agentes comunitário e do auxiliar e técnico em enfermagem da Atenção Básica para o cuidado em saúde mental, conforme especificidade de cada território, qualificando o olhar e a escuta para dar visibilidade à questão das drogas, e ampliar a caixa de ferramenta do desses profissionais do SUS para o cuidado em saúde mental e a construção de territórios de paz.

O itinerário formativo presencial foi executado em todos os estados brasileiros, mantendo uma média de abertura de 600 turmas/mês, distribuídas entre todos os estados do país. Diante da dimensão e da diversidade e complexidade social e cultural que atravessam as relações humanas, a formação de metodologia ativa buscava encontrar caminhos múltiplos de cuidado, centrado nas necessidades de saúde e demandas sociais, priorizando o vínculo para conseguir diminuir o uso prejudicial de drogas. Ou seja, trabalhar para que, em todos os municípios do país, do maior ao menor, existam profissionais de saúde formados e comprometidos com a escuta e o cuidado para com aqueles em situação de vulnerabilidade em função das drogas.

O curso teve como pressuposto que nós não somos individualidades desvinculadas do contexto e do relacionamento com o outro, quer seja família, amigos ou colegas de trabalho. Dessa forma, o consumo de drogas traz consequências que afetam todo o círculo de relacionamento do usuário. Os alunos são estimulados a reconhecer, no território, todo esse conjunto de atores e relações que circundam o consumo de drogas. Em paralelo às primeiras formações, foram articuladas e montadas as Coordenações Estaduais, em estreita parceria com as Escolas Técnicas do SUS (ETSUS) e com o apoio de vários parceiros locais. 


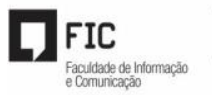

Como já dissemos, o projeto superou a proposta inicial e ofereceu 292.899 vagas, num processo de articulação do cuidado dentro do território e da comunidade. O desafio foi articular um desenho comunicacional, que visa aproximar, cada vez mais, os sujeitos dispersos nas suas especificidades do território, do contexto local e das ações de saúde, visando à sustentabilidade dos Caminhos do Cuidado.

\section{A CONSTRUÇÃO DE PRÁTICAS COMUNICACIONAIS INCLUSIVAS}

A formação dos trabalhadores precisa ser potente para contextualizar e apresentar novas perspectivas técnico-políticas do cuidado em saúde capazes de criar novas dinâmicas de trabalho. O olhar do cuidado ao sujeito e sua condição de saúde deve estar presente nos diferentes espaços da rede do SUS, em especial nos serviços de Atenção Primária de Saúde (APS), os quais devem estar sensibilizados para acolher as pessoas nas suas diferentes demandas e garantir formas de cuidado mais humanizadas, que respeitem os direitos humanos.

A estratégia utilizada foi o diálogo, ferramenta de comunicação capaz de aproximar os sujeitos, estabelecendo uma imensa teia de afetos coordenada e sinérgica entre os envolvidos no processo de formação, desde os diretores das ETSUS, coordenadores estaduais, tutores e alunos. Entendendo aqui o diálogo que considera a escuta do cidadão e sua relação com a sociedade.

De fato, o extrato da comunicação é o entendimento entre os sujeitos que se dá por meio do diálogo. E, para atingir o conhecimento é fundamental que desenvolva uma relação dialógica num processo de aprendizagem. O recurso teórico da semiologia discursiva contribui nessa discussão sobre o papel da linguagem dialógica na organização da hegemonia de determinados grupos sociais em detrimento de outros visando a produção de diferentes imagens e novas formas e ferramentas de comunicá-las. De posse dessa ideia, trago o conceito de dialogismo de Bakhtin (1988) para enfatizar que a lógica do diálogo é a de interações sociais. Conforme cita o autor:

Não tomo consciência de mim mesmo a não ser através dos outros, é deles que recebo as palavras, as formas, a tonalidade que formam a primeira imagem de mim mesmo. Só me torno consciente de mim mesmo revelandome para outro, através do outro e com a ajuda do outro. (BAKHTIN, 1988, p. 121). 
Dialogar é considerar a escuta do cidadão e sua relação com a sociedade e, com base nele, fazer circular uma comunicação capaz de ir além da informação, mas que, de fato, afete o cidadão a ponto de provocar mudanças comportamentais. Segundo Freire (1980, p. 34), não há um sujeito que ensina e um receptor que aprende a respeito de um objeto. O que há são "dois sujeitos que pensam em conjunto, que aprendem um com o outro constituindo um verdadeiro processo comunicacional no qual nenhum deles ensina ao outro, mas ambos aprendem em conjunto a respeito daquele objeto". Nasce aqui à noção do diálogo, baseado numa razão interativa e no pensamento articulado.

Acredito que começar a trilhar por essa abordagem possibilitará a identificação ou pelo menos o reconhecimento dos contextos histórico, social e cultural nos quais os diálogos foram gerados como processo de aproximação para a construção de uma comunicação inclusiva.

O processo constitutivo das ações na relação dialógica no Projeto ocorre "entre aquele que cuida e aquele que é cuidado, uma dimensão típica do campo da saúde”, denominado por Merhy (2004) como a micropolítica do cuidado como encontro.

Ali, existiam sujeitos, territorializados e em desterritorializações, encontrando-se nas suas dificuldades, nas suas comensalidades, nas suas possibilidades, nas suas lutas; o que me permitia olhar os encontros, de territórios-sujeitos em movimento, e tentar criar novas categorias para mirálos e para pensar o que aconteceria, ou poderia acontecer, nesta micropolítica dos encontros. (MERHY, 2004, p. 02).

Nasce aqui uma competência dialógica inclusiva e Merhy (2004), participativa direcionada para o território-sujeito. Significa olhar para esses sujeitos em suas relações, em suas vidas e em seu próprio mundo. Como afirma Petuco (2011, p. 65), “discursos são práticas e produzem efeitos na materialidade da vida cotidiana, incidem sobre políticas públicas, as instituem. Constituem racionalidades e afetos que embasam práticas cotidianas no miúdo da vida vivida".

Quais discursos da política de saúde mental são produzidos pelas e nas ETSUS? Como esses discursos são repassados na forma de conhecimento aos profissionais do SUS? Qual o acúmulo de produção social e a compreensão dos sentidos do elaborado por essas instâncias?

\section{O DIÁlOgO COMO DISPOSITIVO DE APROXIMAÇÃo DO SUJEITO- TERRITÓRIO}


O Projeto Caminhos do Cuidado investiu em estratégias de comunicação para registrar a história em todo o país, indo a cada Escola Técnica procurando ouvi-las. O dispositivo principal utilizado pela comunicação como meio de apropriação da narrativa dos diversos sujeitos envolvidos foi a escuta sensível como aproximação.

A experiência da comunicação inclusiva como dimensão fundamental para mobilizar os profissionais, se materializa quando como pesquisadora e coordenadora de comunicação do Projeto, saí a campo e investi numa conversa de maior potencial comunicativo junto as Escolas de Saúde Pública e Escolas Técnicas do SUS (ETSUS) protagonistas da formação desses profissionais de saúde nas 27 unidades federativas, fortalecendo o sentido da inclusão e do pertencimento das experiências na micropolítica.

As ETSUS estão estruturadas na Rede de Escolas Técnicas do SUS (RETSUS), que completou 15 anos em 2015. Atualmente são 40 escolas técnicas, centros formadores de recursos humanos e escolas de Saúde Pública do SUS em todos os estados do Brasil. As ETSUS, em sua integralidade, estão voltadas para a formação dos trabalhadores de nível médio do sistema de saúde. Dessas 40, 33 são estaduais, seis são municipais e uma é federal. A maioria está vinculada diretamente à gestão do SUS, e as que pertencem a outras secretarias têm gestão compartilhada com a Saúde (RETSUS, 2015). Reconheci nas ETSUS mais do que um canal de aproximação com os profissionais do sistema público de saúde, mas como uns lócus por onde os discursos de educação, comunicação e saúde são apropriados. Espaço interpretativo capaz de nos dizer o sentido relacional entre os profissionais da atenção básica e a política do cuidado.

Assim, especialmente para esse público, a ênfase na escuta foi de grande valia para perceber a intertextualidade que acentua a historicidade dos textos, sempre elos das "cadeias de comunicação verbal” (BAKHTIN, 1998, p. 92). Pois é por meio da comunicação que a mente humana interage com seu ambiente social e natural. Para efeitos de pesquisa, a entrevista semiestruturada foi o instrumento relacional encontrado, fala e escuta, que permitiu estabelecer um vínculo com o sujeito, apropriar dos sentidos dados em seus discursos como prática política e ideológica.

A opção pela modalidade de entrevistas semiestruturadas justifica-se por ser um excelente método de coleta de dados que, segundo Anderson e Knuka (2003, p. 134) são “descritivos na linguagem do próprio sujeito, por meio da comunicação entre indivíduos, permitindo ao investigador desenvolver intuitivamente uma ideia sobre a maneira como os sujeitos interpretam aspetos do mundo". 


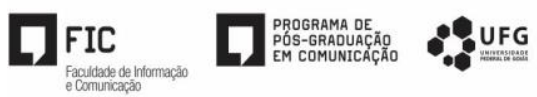

Nessa perspectiva, as entrevistas iluminaram para o olhar do cuidado ao sujeito e sua condição de saúde presentes nos diferentes espaços da rede do SUS, em especial nos serviços de APS, os quais devem estar sensibilizados para acolher as pessoas nas suas diferentes demandas e garantir formas de cuidado mais humanizadas, que respeitem os direitos humanos.

O objetivo entender após a finalização do itinerário formativo, como se deu no território a abordagem de problemas encontrados no processo de trabalho dos profissionais e relacionados ao uso abusivo de crack, álcool e outras drogas na tentativa de ampliar as possibilidades das práticas de cuidado, acolhimento e escuta. E, a partir da análise desses depoimentos poder pensar no reuso desse trabalho para outros projetos do SUS.

“Toda prática social articula diferentes elementos da vida - ação e interação, relações sociais, pessoas (e suas crenças, valores, atitudes, histórias etc.), mundo material e discurso". (FAIRCLOUGH, 2003, p. 205).

Diante disso, a intenção é que as entrevistas semiestruturadas reúnam esses elementos.

\section{Perguntas indutoras}

1. Como o projeto Caminhos do Cuidado chega a você?

2. A equipe foi indicada pela Etsus? Vantagens e desvantagens ser?

3. $\quad$ O que o projeto significou para você?

4. Como avaliaria a execução do projeto? Suas articulações internas e externas?

5. Articulação / atores/ municipio que pactuou com o Plano Crack / alguma "costura institucional que deveria ter sido feita e não foi"'?

6. Um dos objetivos era a integração da atenção básica com a saúde mental. De fato, aconteceu?

7. E como você vê a formação do CC frente ao conjunto de formações pedidas pelo SUS?

8. A relação com as grandes áreas do projeto (Comunicação, Infra, Acadêmico e Pedagógico)

9. Como avalia os papéis do orientador, tutor, comunidade de prática, material pedagógico?

10. Algum relato de aluno que tenha lhe chamado atenção após a formação?

11. O que Projeto deixa como legado para a Escola?

12. Caso estivesse na gestão do projeto, o que faria diferente?

Perseguindo o caminho da escuta e da interação com o entrevistado incluí mais um elemento à pesquisa a introdução do vídeo para dar visibilidade às reações e percepções dos 
entrevistados. Assim, busquei manter o foco tão somente naquilo que podia ser apreendido na observação cuidadosa dos enunciados os quais me propus percorrer.

Consegui os contatos e endereços das ETSUS e dos coordenadores estaduais do Projeto Caminhos do Cuidado que foram fornecidos pelo Instituto de Comunicação e Informação Científica e Tecnológica em Saúde (ICICT) da Fiocruz ${ }^{2}$, no mês de março de 2015, quando iniciei a troca de e-mails com os coordenadores daqueles estados que já tinham atingido a meta de capacitação dos agentes comunitários de saúde e auxiliares e técnicos de enfermagem.

Mas para que a mensagem seja eficaz, o receptor deve estar pronto para recebê-la, melhor dizendo, deve haver um consentimento para a conversação. O contexto naquele momento era propício, já que todos os estados obtiveram resultados exitosos, medidos não apenas pela superação da meta quantitativa prevista inicialmente, mas também pela potência que o projeto se tornou ao deixar marcas nos territórios por onde percorreu e nos atores envolvidos no processo de formação. Assim, percorri as Escolas como pesquisadora e coordenadora da área de comunicação do Projeto Caminhos do Cuidado.

Tão logo era confirmada a data, eu me preparava para a entrada no território tendo em mãos o relatório técnico elaborado pela equipe estadual, base de dado fundamental nesse processo de avaliação. Nele pude conhecer os dados do território, pontos fortes e fracos do processo formativo e o perfil de cada coordenador estadual. Somada a essa leitura, por precaução estabelecia uma conversa prévia por telefone a fim de entender o contexto situacional.

Mapeei como proposta inicial visitar de três a quatro estados por mês. Mas, ao começar as viagens, as marcações, de fato, se deram muito mais pela disponibilidade dos entrevistados. Resultado, um ziguezague pelo Brasil cruzando os 26 Estados e mais o Distrito Federal, no período de 17 semanas, perfazendo um total de 56 voos e 61entrevistas realizadas.

A cada viagem eu escrevia um diário de pesquisa com perguntas básicas do jornalismo (quando, onde, quem, por que, o que e como) e as minhas impressões do campo. Além do registro fotográfico dos atores e do território. O diário era complementado com as transcrições das entrevistas que eram realizadas na noite do mesmo dia no hotel ou nas longas horas de espera em salas dos aeroportos para que as informações e as percepções estivessem ainda vivas em minha memória.

2 Por atuar no Projeto Caminhos do Cuidado, gestado pelo Instituto de Comunicação e Informação Científica e Tecnológica em Saúde (ICICT) da Fiocruz, fazendo entrevistas com os diretores das Escolas Técnicas do SUS, por meio da pesquisadora Maria Cristina Guimarães foi possível viabilizar a pesquisa de campo para esta tese. 


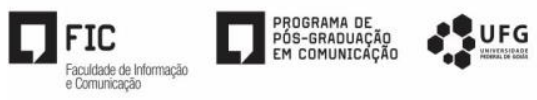

Ao término das viagens, fiz uma primeira leitura das entrevistas e o reconhecimento dos grandes eixos discursivos. Logo entendi que os regimes oral e escrito impregnaram o trabalho de campo, e, conforme dito por Williams (1977, p. 21-44), deram o sentido relacional desse processo constitutivo do homem. A oralidade e a escrita aqui foram componentes indissociáveis de desejo, valor e expressão da esfera no território.

\section{RESULTADOS}

Enfim, foram 17 semanas num percurso sensível a mudanças de cores, cheiros, cultura, temperatura, arquitetura e acolhimento dos sujeitos. Elementos iam se agregando e conformando as marcas de cada entrevistado, uma plástica de expressões e sentidos que possibilitavam uma apreensão significante. Oliveira e Teixeira (2009, p. 82) assim explica essa dinâmica: “o sujeito da enunciação assume não só posicionamentos, mas também posturas e posições em relação ao outro na sua experiência em que prova (e põe à prova) o sentido que constrói”.

A partir daí, fiz várias leituras para proceder aos recortes e classificações. A primeira classificação aplicada começa na própria lógica das dimensões no bojo das perguntas. Numa segunda etapa, agrupei todas as respostas de cada pergunta de todos os entrevistados. Esse novo grupamento foi manuseado e retomado quantas vezes necessárias até se tornar uma “linguagem apreendida". (NETO, 2014).

Busquei não ficar amarrada à estrutura dos textos transcritos. Eu me apoiei em Araujo e Cardoso (2007), que compreendem a comunicação como processo dinâmico e que "cada fala, enunciado ou discurso integra uma rede de significações, que é parte de suas condições de produção". Assim, acrescentei outros potentes elementos trazidos pelas imagens, como expressões, gestos, intertextos, conversa de pano de fundo e subtextos. Estava atenta a essas conversações, expressões, falas e sotaques produzidos pelos entrevistados, discursos pessoais e discursos oriundos de suas posições enquanto representantes institucionais, processos próprios dessa nova prática comunicativa.

Considerando os diferentes sentidos produzidos pelos entrevistados, a intenção foi poder transitar entre essas manifestações de expressões oral, escrita e, nesse percurso, relacioná-las para que, ao fim e ao cabo, essas partes se integrassem numa totalidade capaz de desvendar as suas apreensões. 
Ainda levamos em consideração a teoria dos gêneros do discurso produzida por Bakhtin (2003). Na reinterpretação de Sacramento e Cruz (2014), os gêneros contam com três elementos indissolúveis relacionados ao todo do enunciado e determinados pelo campo da comunicação discursiva: o conteúdo temático, o estilo e a construção composicional. Os enunciados não se bastam em si mesmos: uns conhecem os outros e se refletem uns nos outros. Para Bakhtin, esse "dialogismo" faz com que as "marcas enunciativas sejam partes específicas da tessitura social mediadas pela linguagem de certo gênero discursivo, ao mesmo tempo em que são construídas por ela".

Como resultado alguns marcadores puderam ser evidenciados como o perfil dos diretores das Escolas Técnicas que é predominantemente feminino. O mesmo acontece entre os coordenadores estaduais do Projeto Caminhos do Cuidado. Dos 62 entrevistados, 54 eram mulheres e apenas oito, homens. Do total, 38 têm mais de 40 anos e 24 estão abaixo dessa faixa etária. As escolhas profissionais estão relacionadas aqui com o conteúdo temático saúde e educação. Como dissemos acima, Bakhtin define como marca enunciativa aquilo que pode ser dito em determinado gênero, os temas típicos que irão refletir lá na frente na produção discursiva do sujeito. O maior número é de enfermeiras (18), pedagogas (11) e psicólogas (8). Na sequência, assistentes sociais (5), odontólogas (4), fisioterapeutas com especialização em saúde (3), farmacêuticos (3), administradores (3) e professores de educação física (2). Os restantes com apenas um representante: jornalista, historiador, sanitarista, médico, nutricionista, economista e advogado. Os "marcadores dos atores" revelaram a predominância do gênero feminino, de meia-idade, profissionais do campo da saúde com especialização e/ou mestrado, em sua maioria profissionais da rede de saúde pública, poucos com passagem na rede privada.

A posição funcional no mundo do trabalho é outro marcador. Foram 29 diretores de Escola, 26 coordenadores estaduais do Curso de Formação dos Agentes Comunitários de Saúde, Auxiliares e Técnicos de Enfermagem em crack, álcool e outras drogas, e dois tutores e cinco orientadores do referido curso. Destacamos a posição, pois nela emergem relações de poder que dão suporte a diferentes ideologias construídas por meio do discurso e das práticas sociais. Numa visão "foucaultiana", todo uso da linguagem é político, pois posiciona os atores sociais de forma específica e engendra hierarquias. Segundo o autor:

É somente nessas relações de luta e de poder - na maneira como as coisas entre si, os homens entre si se odeiam, lutam, procuram dominar uns aos outros, querem exercer, uns sobre os outros, relações de poder, que 
compreendemos em que consiste o conhecimento. (FOUCAULT, 2001, p. 23).

O cargo de direção das ETSUS é ocupado por meio de indicações políticas por estar vinculado, em sua maioria, às Secretarias Estaduais de Saúde. Isso gera dificuldades nesse processo, pois os atores responsáveis pela educação permanente dos profissionais de nível técnico do SUS ocupam cargos de confiança de grande rotatividade e instabilidade.

Essa fragilidade estrutural pôde ser claramente percebida durante as minhas viagens. Nos meses das entrevistas ocorriam mudanças dos governos estaduais e, consequentemente, as escolas também estavam passando por alteração de direção. Era nítido o poder do discurso daqueles diretores recém-chegados em relação aos que permaneceram em seus cargos voltados para a educação permanente no Estado. A apropriação na fala, gestos e domínio dos espaços territoriais faz valer a afirmação de Foucault em evidenciar a existência do discurso não só como um lugar, mas sim estabelecer suas ligações com o poder, tornando-o um lugar de poder. Como define Costa,

O discurso, dessa forma, não seria só o meio através do qual se exerce o poder, mas também o lugar pelo qual se luta para exercê-lo. Luta-se por meio do discurso, no discurso, pelo discurso. O poder dentro desse lugar é uma questão de inscrição na Ordem do Discurso, de legitimação como pessoa que tem o direito de fala. (COSTA, 2009)

A expressão do poder também pode ser vista na própria potência da Escola como aparelho formador da metodologia pedagógica e estruturação de rede no território à autonomia financeira.

Já em relação aos denominados coordenadores estaduais, responsáveis pelo desenvolvimento do curso no estado, a forma de ingresso ocorreu por meio de edital, mas a escolha dos profissionais selecionados foi contagiada também por interesses políticos. Muitas indicações ocorreram por mérito; no currículo, a experiência com o tema da atenção básica e saúde mental; mas outras aconteceram por indicações políticas ou pela proximidade com a direção da Escola.

Uma particularidade: os sujeitos que se denominavam militantes do SUS mostraram maior crença e compromisso com o trabalho enfrentando as dificuldades e não deixando esmorecer. Trago a teoria do poder simbólico de Bourdieu (2002), do "poder de fazer ver e fazer crer", que se refere ao poder da palavra de constituir a realidade. A palavra-chave aqui é legitimidade. Sem ela, o poder de comunicação esvaeceria nos discursos dos coordenadores e diretores de Escola. O que faz o poder das palavras, poder manter a ordem ou subvertê-la, é a crença na legitimidade delas e daquele que as pronuncia, crença cuja produção não é de 
competência das palavras. E os capitais econômicos, culturais e sociais, quando reconhecidos como legítimos, convertiam-se claramente em capital simbólico.

Ver o vídeo, ouvir e transcrever a fala, reler os relatórios foi um processo de transformação de linguagens que gera múltiplas interpretações e novos elemento de pesquisa a ser incluído nos regimes oral e escrito criando uma composição partilhada. Essa ideia de acumulação de instrumentos e caminhos objetiva "contemplar a totalidade dos textos manifestados em qualquer materialidade e, por outro lado, definir as estratégias enunciativas particulares dos textos concretos" (Oliveira e Teixeira, 2009).

Esse exercício resultou na criação de um canal denominado de um canal "Memórias do Caminho", no sítio http://observatorio.caminhosdocuidado.org/memorias-do-caminho, um acervo de depoimentos que correspondem à "literatura primária" publicado de forma restrita na plataforma YouTube, exatamente na forma com que foram produzidos. E após edição, essa estratégia discursiva torna-se fonte secundária publicada de forma irrestrita no Observatório Caminhos do Cuidado (link: https://goo.gl/CJZQzj). Nessa perspectiva percebeu-se que a linguagem do país inteiro não tinha diversidade que era única, sendo, de fato, a do cuidado "entre aquele que cuida e aquele que é cuidado".

Outro resultado que utilizou como dado essa comunicação interpessoal foram os relatórios de 2015 e 2016, que pode ser acessado no link: http://observatorio.caminhosdocuidado.org/comunicacao. A consolidação desses dados dá visibilidade às principais potencialidades e fragilidades do projeto, sendo um instrumento importante de consulta e avaliação do próprio Caminhos do Cuidado e para outras ações de formação no país. Essas e outras práticas comunicacionais podem ser conferidas na íntegra no Observatório Caminhos do Cuidado (www.observatorio.caminhosdocuidado.org).

\section{CONSIDERAÇÕES FINAIS}

A intenção desse artigo foi instigar o diálogo de dois campos do conhecimento comunicação e educação - nas políticas públicas de saúde, contribuindo para o processo de aprendizagem dos seus profissionais.

O desafio foi nos lançar a campo, comunicar, dialogar com aqueles que fazem e passam pelo processo formativo, na expectativa de entender como essa política educacional em larga escala se deu no território. Essa audiência deu-nos algumas respostas que hoje 
compõem o banco de dados do Observatório do Caminhos do Cuidado.Todavia existem outras dimensões nesse caminho que mereciam ser investigadas.

Surgem nesse estudo propostas de um fazer diferente, utilizar das ferramentas do campo da comunicação para coordenar uma rede de emoções e afetamentos verdadeiras ligações entre sujeitos aderentes ao Projeto Caminhos de Cuidado. Um compromisso relacional que se dá até hoje (2017) entre os integrantes dessa rede imersos na avaliação desse processo formativo diferenciado e na reflexão sobre quais foram as mudanças provocadas nos sentidos dessa população vulnerável, que são os usuários de crack, álcool e outras drogas. O que as pessoas têm a dizer que vai para além da eficácia?

Esse é o desafio atual, entrelaçar essa memória, experiência, narrativa num processo avaliativo de um projeto de larga escala, que relacionou pessoas de cada canto desse país. Uma avaliação que tem em seus pressupostos rotas que continuam o que o projeto Caminhos do Cuidado afirmou em sua execução, a valorização do saber do território e das experiências e aprendizados singulares que o mesmo coloca para os trabalhadores e trabalhadoras da área da saúde. Seguindo os preceitos consagrados da Educação Permanente em Saúde, que visam um aprendizado que é cantado pelos desafios do cotidiano, e que somente a partir deste cotidiano, que está sempre em constante transformação, é possível criar sentidos que se desenham a partir de uma concepção que concebe o saber em que há lugar para o saber da experiência de quem vive.

\section{REFERÊNCIAS}

ANDERSON, T.; KNUKA, H. e-Research, Methods, Strategies and Issues. USA: Person Education, 2003.

ARAUJO I. S.; CARDOSO J. M. Comunicação e Saúde. Rio de Janeiro: Editora FIOCRUZ, 2007. 152 p. (Coleção Temas em Saúde).

BAKHTIN, M.; VOLOCHINOV, V. N. [1929] Marxismo e filosofia da linguagem. Trad. M. Lahud e Y. F. Vieira. São Paulo: Hucitec, 1988.

Os gêneros do discurso. In: BAKHTIN, M. Estética da criação verbal. São. Paulo: Martins Fontes, 2003.

BOURDIEU, P. A escola conservadora: as desigualdades frente à escola e à cultura Tradução Gouveia, A. J. In: NOGUEIRA, M. A.; CATANI, A. (Org.). Escritos e Educação. Petrópolis, RJ: Vozes, 2002. p. 39-64.

COSTA, L.P.A. A ADC Faircloughiana: Concepções e Reflexões. Revista Linguagem, 2009. 
FAIRCLOUGH, N. Analysing Discourse: Textual Analysis for Social Research. London: Routledge. 2003.

FOUCAULT, M. A verdade e as formas jurídicas. 2. ed. Rio de Janeiro: Departamento de Letras PUC-Rio, 2001.

FREIRE, P. Extensão ou Comunicação? Rio de Janeiro: Paz e Terra. 1980.

MERHY, E. E. Cuidado com o Cuidado em saúde: saiba explorar seus paradoxos para defender a vida. Campinas, 2004.

NETO, J.C.F. Tábuas da lei e surras de gato morto: ética e comunicação na encruzilhada do escrito e do oral. In: SACRAMENTO, I.; MATHEUS, L. (Org.). História da Comunicação: experiências e perspectivas. Mauad: Rio de Janeiro, 2014.

OLIVEIRA, A.C.; TEIXEIRA, L. (Org.). Linguagens na Comunicação: desenvolvimento de semiótica sincrética. São Paulo: Estação das Letras e das Cores, 2009.

PETUCO, Dênis. Entre imagens e palavras: o discurso de uma campanha de prevenção ao crack. 2011. 131 f. Dissertação (Mestrado em Educação) - Centro de Ciências Humanas, Letras e Humanidades, Universidade Federal da Paraíba, João Pessoa, 2011.

SACRAMENTO, I.; CRUZ, C. A patologização da obesidade: endereçamentos da moralidade corporal contemporânea em um programa de TV. In: Lerner, Kátia (Org). Saúde e Jornalismo: interfaces contemporâneas. Rio de Janeiro: Editora Fiocruz, 2014.

WILLIAMS, R. Marxism and literature. Oxford University Press: Oxford, 1977. p. 21-44. 